\title{
Teores de pigmentos, fluorescência da clorofila $a$ e índice SPAD em cultivares de girassol sob regimes hídricos
}

Pigment content, chlorophyll a fluorescence and index SPAD in sunflower cultivars under water regimes

\author{
Sebastião de Oliveira Maia Júnior ${ }^{1}$, Jailma Ribeiro de Andrade ${ }^{1}$, Rosinaldo de Sousa Ferreira ${ }^{2}$, Danila \\ Lima de Araújo ${ }^{2}$, Hugo Orlando Carvallo Guerra ${ }^{3}$, Flaviana Gonçalves da Silva ${ }^{4}$
}

${ }^{1}$ Universidade Federal de Alagoas - UFAL, BR-104 Norte Km 85 s/n, Rio Largo - AL, ${ }^{2}$ Universidade Federal da Paraíba - UFPB, Rodovia PB 079 - Km 12, Areia - PB, ${ }^{3}$ Universidade Federal de Campina Grande UFCG, Av. Aprígio Veloso, 882 - Bodocongó, Campina Grande - PB, ${ }^{4}$ Universidade Federal de Sergipe UFS, Av. Marechal Rondon, s/n, São Cristóvão-SE. email: juniormaiagrari@hotmail.com

Recebido em: 22/09/2014 Aceito em:20/07/2017

Resumo. O girassol (Helianthus annuus L.) é uma espécie vegetal que apresenta inúmeras aplicações na atualidade, sendo considerada uma das plantas que apresenta um potencial máximo de sua produção. Objetivou-se com este trabalho avaliar aspectos fotossintéticos de cultivares de girassol, submetidas a diferentes regimes hídricos. O trabalho foi realizado em casa de vegetação, nas instalações pertencentes ao Departamento de Engenharia Agrícola da UFCG, conduzido em delineamento inteiramente casualizado em esquema fatorial $3 \times 4$ (três cultivares e quatro níveis de irrigação) com quatro repetições. Foram utilizados vasos com capacidade para $100 \mathrm{~L}$, tendo-se o conteúdo de água do solo monitorado diariamente por meio de uma sonda de capacitância, modelo DIVINER 2000®, segmentada nos tratamentos com $100 \%$ da capacidade de campo (CC). Foram avaliadas as características: fluorescência da clorofila $a$, teores de clorofila $a, b$ e total, e índice relativo SPAD. Houve diferença estatística entre as cultivares para o índice relativo de clorofila e o teor de carotenoides, e entre os regimes hídricos para os teores de clorofila $b$ e clorofila total. Houve correlação entre o índice de clorofila (SPAD) e o teor de clorofila total. Os regimes hídricos não alteraram a fluorescência e o teor da clorofila $a$, entretanto, alteraram os teores de clorofila $b$ e total em plantas de girassol.

Palavras-chave: consumo hídrico, fisiologia, Helianthus annuus L.

Abstract. The sunflower (Helianthus annuus L.) is a plant species that has many applications today, and is considered one of the plants that has a maximum potential production. The objective of this study was to evaluate photosynthetic aspects of sunflower cultivars, under different water regimes. The study was conducted in a greenhouse at the premises belonging to the Department of Agricultural Engineering UFCG, conducted in a completely randomized design in a factorial $3 \times 4$ (three varieties and four levels of irrigation) with four replications. Were used vessels with a capacity of $100 \mathrm{~L}$, having the water content of the soil monitored daily by means of a capacitance probe, Model 2000 ® DIVINER, targeted treatments in 100\% of field capacity (CC). The characteristics evaluated were: chlorophyll fluorescence, content of chlorophyll a, b and total, and index relative SPAD. There was statistical difference among cultivars for index relative chlorophyll and content of carotenoids, and between water regimes on the content of chlorophyll $\mathrm{b}$ and total chlorophyll. A correlation between the chlorophyll index (SPAD) and total chlorophyll content. Water regimes did not alter the fluorescence and the content of chlorophyll a, however, altered the levels of chlorophyll b and total in sunflower plants.

Keywords: Helianthus annuus L., physiology, water absorption

\section{Introdução}

O girassol (Helianthus annuus L.) é uma espécie vegetal originária das Américas, de ciclo anual, pertencente à família Asteraceae, com inúmeras aplicações na atualidade e, considerada uma das plantas que apresenta um potencial máximo de sua produção, podendo ser utilizado na alimentação humana, na ração de animais e na

Maia Junior et al., v.10, n.36, p. 105-112, Dourados, 2017 


\section{(ㅇ)}

\section{Revista Agrarian}

ISSN: 1984-2538

produção de Biodiesel, além de apresentar aptidão ornamental (Dickmann et al., 2005).

Contudo, as poucas informações disponíveis sobre cultivares adaptados (Capone et al., 2012) é fator ideal e decisivo para assegurar a rentabilidade da cultura (Paes et al., 2009), e formas de manejo apropriadas, como a prática da irrigação.

Geralmente, a falta ou o excesso de água numa cultura é prejudicial ao seu desenvolvimento. O déficit hídrico caracterizado pela redução do conteúdo de água no solo é o maior problema enfrentado pela agricultura e a habilidade de tolerância à seca é de grande importância. $\mathrm{O}$ estresse por escassez de água desencadeia uma ampla variedade de respostas no vegetal, como alterações na expressão genética e metabolismo celular, diminuições nas taxas de crescimento e produtividade, bem como, a inibição de vários processos fisiológicos (Carneiro, 2011). De outro modo, o excesso acarreta na falta de oxigênio para as raízes, o que provoca a morte dos tecidos radiculares por favorecer a fermentação lática, podendo também levar a redução na absorção de nutrientes e água por falta de energia (Taiz \& Zeiger, 2009). Diante estes aspectos, as plantas podem responder com a limitação na síntese de clorofila (Dutra et al., 2012).

A análise da fluorescência da clorofila $a$ vem sendo amplamente utilizada no entendimento dos mecanismos da fotossíntese propriamente dito, bem como na avaliação da capacidade fotossintética alterada por estresses bióticos ou abióticos pelos quais as plantas possam passar (Catunda et al., 2005), entre os quais pode-se incluir o estresse hídrico.

As clorofilas exercem um controle dominante sobre a quantidade de radiação solar absorvida pelas plantas e por essa razão as suas concentrações foliares exercem uma estreita relação com as taxas fotossintéticas (Streit et al., 2005). A eficiência fotossintética por está ligada ao teor de clorofila das plantas, afeta o crescimento e a adaptabilidade das mesmas ao ambiente o qual se encontram. Logo, o teor de clorofila nas folhas é um indicador do nível de dano que determinado estresse pode causar ao vegetal (Catunda et al., 2005).

Além do teor de clorofila e da eficiência fotossintética, o conteúdo de carotenoides nas folhas indica também o nível de dano que determinado estresse pode estar causando à planta, já que a clorose é, normalmente, um dos primeiros sintomas expressos (Catunda et al., 2005; Streit et al., 2005).

A quantificação do conteúdo de clorofilas em folhas pode ser realizada via maceração com acetona, e posterior leitura em espectrofotômetro. Entretanto, este método resulta na coleta destrutiva do material vegetal e é relativamente demorado (Amarante et al., 2009). De outro modo, pode ser analisado também o índice relativo de clorofila que permite diagnosticar a integridade do aparato fotossintético das plantas que estão submetidas a adversidades ambientais tais como o déficit hídrico (Magalhães et al., 2010) podendo ser determinado através de um medidor portátil SPAD-502 que permite leituras instantâneas de clorofila sem destruição do material vegetal, fazendo com que tal método seja caracterizado pela simplicidade e rapidez, além de, apresentar-se tão eficiente quanto o obtido por espectrofotometria (Argenta et al., 2001).

Nesse contexto, objetivou-se com o presente trabalho avaliar aspectos fotossintéticos em cultivares de girassol submetidas a diferentes regimes hídricos, visando identificar respostas ocasionadas pelo estresse hídrico.

\section{Material e Métodos}

O trabalho foi realizado em casa de vegetação, nas instalações pertencentes ao Departamento de Engenharia Agrícola (Deag) do Centro de Tecnologia e Recursos Naturais da Universidade Federal de Campina Grande, no período compreendido entre julho e novembro de 2012. O local fica situado a $7^{\circ} 12^{\prime} 88^{\prime \prime}$ de latitude Sul, 35०54'40" de longitude Oeste e altitude de 532 $\mathrm{m}$; o clima da região, conforme a classificação climática de Köppen, é do tipo Csa, que representa clima mesotérmico, subúmido, com período de estiagem quente e seco (4 a 5 meses) e período chuvoso de outono a inverno.

$\mathrm{O}$ experimento foi conduzido com três cultivares de girassol: BRS Gira 26, Agrobel 962 e Embrapa 122/V2000, representando dois híbridos e uma variedade, respectivamente; submetidas a quatro lâminas de irrigação, sendo elas: 40, 60, 80 e $100 \%$ do conteúdo de água do solo na capacidade de campo.

O delineamento experimental adotado foi o inteiramente casualizado em esquema fatorial $3 \mathrm{x}$ 4, composto pelas três cultivares e quatro níveis de 


\section{Revista Agrarian}

ISSN: 1984-2538

irrigação originando doze tratamentos com quatro repetições cada, resultando assim, 48 unidades experimentais. As unidades experimentais consistiram de um vaso plástico com capacidade aproximada para $100 \mathrm{~L}$, e arranjados em espaçamento de 0,20 e $1,5 \mathrm{~m}$. Os vasos foram dispostos sobre tijolos para permitir a drenagem, caso ocorresse, e posteriormente preenchidos com $110 \mathrm{~kg}$ de solo após o peneiramento deste em malha de $2 \mathrm{~mm}$ de diâmetro. $\mathrm{O}$ solo utilizado foi um
Neossolo Regolítico (Embrapa, 2006) proveniente de área pertencente a Empresa de Pesquisa Agropecuária da Paraíba (EMEPA) localizada no município de Lagoa Seca. Amostras de solo foram coletadas entre 0,20 e $0,60 \mathrm{~m}$ de profundidade, e levadas para o Laboratório de Irrigação e Salinidade (LIS) do Departamento de Engenharia Agrícola para análises físico-hídrica e química (Tabelas 1 e 2).

Tabela 1. Análise físico-hídrica do solo utilizado. Campina Grande-PB, 2012

\begin{tabular}{lc}
\hline Características físicas do solo & $(20-60 \mathrm{~cm})$ \\
\hline Areia (\%) & 77,70 \\
Silte (\%) & 11,29 \\
Argila (\%) & 11,01 \\
Classificação textural & Franco Arenoso \\
Densidade do solo $\left(\mathrm{g} \mathrm{cm}^{-3}\right)$ & 1,40 \\
Densidade de partículas $\left(\mathrm{g} \mathrm{cm}^{-3}\right)$ & 2,67 \\
Porosidade (\%) & 47,57 \\
\hline Umidade (\%) & \\
Natural & 0,80 \\
0,10 atm & 13,22 \\
15,0 atm & 3,77 \\
Água disponível & 9,45 \\
\hline
\end{tabular}

Tabela 2. Análise química do solo utilizado. Campina Grande-PB, 2012

\begin{tabular}{|c|c|}
\hline Características químicas do solo & $(20-60 \mathrm{~cm})$ \\
\hline Cálcio $\left(\mathrm{cmol} / \mathrm{dm}^{3}\right.$ de solo) & 0,51 \\
\hline Sódio $\left(\mathrm{cmol} / \mathrm{dm}^{3} \mathrm{de}\right.$ solo) & 0,05 \\
\hline Magnésio ( $\mathrm{cmol} / \mathrm{dm}^{3} \mathrm{de}$ solo) & 0,20 \\
\hline Potássio $\left(\mathrm{cmol} / \mathrm{dm}^{3}\right.$ de solo $)$ & 0,18 \\
\hline Fósforo $\left(\mathrm{mg} / \mathrm{dm}^{3}\right)$ & 5,4 \\
\hline $\mathrm{pH} \mathrm{H} \mathrm{H}_{2} \mathrm{O}(1: 2,5)$ & 4,8 \\
\hline Hidrogênio ( $\mathrm{cmol} / \mathrm{dm}^{3} \mathrm{de}$ solo) & 0,56 \\
\hline Alumínio ( $\mathrm{cmol} / \mathrm{dm}^{3} \mathrm{de}$ solo) & 0,40 \\
\hline CTC ( $\mathrm{cmol} / \mathrm{dm}^{3}$ de solo) & 1,50 \\
\hline
\end{tabular}

A acidez do solo foi corrigida 60 dias antes do plantio, com $\mathrm{CaCO}_{3}$ de PRNT de $95 \%$, visando elevar o índice de saturação por bases ao valor de $70 \%$.

A adubação foi realizada conforme indicações de Lira et al. (2011), em que se aplicou N-P-K (40-80-80) utilizando-se ureia, superfosfato triplo e cloreto de potássio, respectivamente. As adubações foram aplicadas em fundação, exceto o $\mathrm{N}$, que teve $70 \%$ aplicados 30 DAS (dias após semeadura). A adubação boratada foi fornecida 20 DAS utilizando-se como fonte o ácido bórico em proporções equivalentes a $2 \mathrm{~kg} / \mathrm{ha}$.
O solo foi irrigado próximo da capacidade de campo antes da semeadura, que ocorreu em julho de 2012, com o intuito de garantir umidade adequada para uma boa germinação das sementes e emergência das plântulas. As sementes de melhor aparência foram selecionadas e colocadas cinco em cada vaso. A partir de então os vasos foram irrigados uniformemente a $100 \%$ da capacidade de campo (CC) até a estabilização da emergência; 15 dias após a semeadura se realizou o desbaste deixando-se uma planta (a mais vigorosa) por vaso, por conseguinte foram implantados os tratamentos 


\section{(-)}

\section{Revista Agrarian}

ISSN: 1984-2538

de água que prosseguiram até o final do experimento.

O conteúdo de água do solo foi monitorado diariamente por meio de uma sonda de capacitância, modelo DIVINER 2000®, segmentada nos tratamentos com $100 \%$ da capacidade de campo (CC), em camadas de $0,10 \mathrm{~m}$, até $0,60 \mathrm{~m}$ de profundidade, a partir de 15 dias após a semeadura até o final do ciclo da cultura. Com base nas leituras da sonda foi feito o balanço de água que contabilizou o consumo da mesma pelo referido tratamento e a partir do qual, contabilizaram-se as lâminas correspondentes aos demais tratamentos, os quais foram mantidos a 40 , 60 e $80 \%$ da CC. A irrigação procedeu-se manualmente com uma proveta graduada em milílitros.

Durante a condução do experimento, sempre que necessário, procederam-se tratos culturais e controle fitossanitário, seguindo recomendações de Leite et al. (2005).

Foram realizadas as seguintes avaliações: Fluorescência da clorofila a, índice relativo de clorofila, teores de clorofila $a$, clorofila $b$, clorofila total e carotenoides e, correlações entre o índice relativo de clorofila e o teor de clorofila a, de clorofila $b$, de clorofila total e de carotenoides.

As medições dos parâmetros relacionados à fluorescência da clorofila $a(\mathrm{Chl} a)$, foram mensurados aos 45 DAS, em folhas apresentando bom estado fitossanitário e completamente expandidas do terço superior das plantas, utilizando-se um fluorômetro portátil PEA (Plant Efficiency Analyser, Hansatech Norfolk, UK), no horário compreendido entre 10:00 e 12:00 hs do dia. As folhas selecionadas foram adaptadas ao escuro durante um período de 30 minutos, utilizando-se clipes apropriados. Após a adaptação, as folhas foram expostas a pulso saturante de luz, obtendo-se as respostas relacionadas aos transientes da fluorescência da clorofila $a$ : fluorescência inicial $\left(\mathrm{F}_{0}\right)$, fluorescência variável $\left(F_{v}\right)$, fluorescência máxima $\left(F_{m}\right)$ e eficiência máxima do fotossistema II $\left(\mathrm{F}_{\mathrm{v}} / \mathrm{F}_{\mathrm{m}}\right)$.

As avaliações do índice relativo de clorofila (IRC) foram realizadas aos 45 dias após semeadura, utilizando-se o clorofilômetro portátil SPAD-502 em folhas do terço superior que se encontravam em bom estado fitossanitário. Para tanto, efetuaram-se três leituras em pontos distintos de uma folha por planta e calculou-se a média.

Os teores de clorofilas e de carotenoides foram determinados com amostras de discos foliares vazados de uma folha do terço superior de cada planta aos $50 \mathrm{DAS}$, procedendo-se à pesagem de cada material. Posteriormente, o material foi macerado e acondicionados em recipientes contendo $6 \mathrm{ml}$ de acetona $80 \%(\mathrm{v} / \mathrm{v})$. Os recipientes ficaram sob refrigeração $\left(8^{\circ} \mathrm{C}\right)$ por 48 horas e, posteriormente, foram filtrados. Após a filtragem do sobrenadante foram calculados os teores de clorofila $a, b$, total $(a+b)$ e de carotenoides de acordo com Lichtenthaler (1987), a partir da absorbância da solução obtida por espectrofotometria a 647, 663 e $470 \mathrm{~nm}$, respectivamente. Os resultados foram expressos em $\mathrm{mg} \mathrm{g}^{-1}$ de matéria fresca (MF).

Os dados das variáveis foram submetidos à análise de variância (Teste $\mathrm{F}$ ) ao nível de $5 \%$ de probabilidade. Em caso de significância as variáveis qualitativas foram avaliadas através do teste de Tukey e as quantitativas por meio de regressão, utilizando-se o software SISVAR (Ferreira, 2000).

Quanto aos dados referentes às correlações foram submetidos a correlação linear de Pearson, analisadas pelo valor de (r) entre as variáveis estudadas.

\section{Resultados e Discussão}

Não se observou diferença significativa entre as cultivares, regimes hídricos, tampouco da interação destes para as variáveis fluorescência inicial $\left(\mathrm{F}_{0}\right)$, fluorescência máxima $\left(\mathrm{F}_{\mathrm{m}}\right)$, fluorescência variável $\left(\mathrm{F}_{\mathrm{v}}\right)$ e eficiência quântica máxima do fotossistema II $\left(\mathrm{F}_{\mathrm{v}} / \mathrm{F}_{\mathrm{m}}\right)$ (Tabela 3$)$. Assim como nesse estudo, Hura et al. (2007) também não verificaram influência da limitação hídrica sobre a eficiência máxima do fotossistema II em plantas de trigo. 


\section{(-) \\ Revista Agrarian \\ ISSN: 1984-2538}

Tabela 3. Resumo do teste $\mathrm{F}$ para os parâmetros da fluorescência da clorofila $a$ : fluorescência inicial $\left(\mathrm{F}_{0}\right)$, fluorescência máxima $(\mathrm{Fm})$, fluorescência variável $(\mathrm{Fv})$ e eficiência quântica do fotossistema II $(\mathrm{Fv} / \mathrm{Fm}) \mathrm{de}$ cultivares de girassol sob diferentes regimes hídricos

\begin{tabular}{cccccc}
\hline \multirow{2}{*}{ FV } & \multirow{2}{*}{ GL } & \multicolumn{4}{c}{ Quadrados Médios } \\
\cline { 3 - 6 } & & $\mathrm{F}_{0}$ & $\mathrm{Fm}$ & $\mathrm{Fv}$ & Fv/Fm \\
\hline C & 2 & $573,81^{\text {ns }}$ & $32569,56^{\text {ns }}$ & $12087,77^{\text {ns }}$ & $0,000040^{\text {ns }}$ \\
RH & 3 & $200,50^{\text {ns }}$ & $13930,46^{\text {ns }}$ & $3440,02^{\text {ns }}$ & $0,000041^{\text {ns }}$ \\
C x RH & 6 & $404,89^{\text {ns }}$ & $2868,92^{\text {ns }}$ & $8902,215^{\text {ns }}$ & $0,000145^{\text {ns }}$ \\
Resíduo & 36 & 300,04 & 14472,35 & 16332,58 & 0,000067 \\
CV \% & & 5,72 & 6,26 & 7,86 & 0,98 \\
\hline
\end{tabular}

Nota: $\mathrm{FV}=$ Fontes de Variação, $\mathrm{GL}=$ Graus de Liberdade, $\mathrm{CV}=$ Coeficiente de variação, $\mathrm{C}=$ Cultivares, $\mathrm{RH}=$ Regimes Hídricos e ns= não significativo pelo teste $\mathrm{F}$.

O índice relativo de clorofila apresentou diferença significativa entre as cultivares. Entretanto, não foram verificadas diferenças estatísticas significativas dos regimes hídricos, bem como da interação destes com as cultivares (Tabela 4). Resultados semelhantes foram observados por Dutra et al. (2012) que avaliando o desenvolvimento de plantas de girassol sob diferentes condições de fornecimento de água também não constataram diferença estatística significativa das diferentes disponibilidades hídricas para o índice de clorofila SPAD.

O comportamento do índice relativo de clorofila entre as cultivares revelou a Agrobel 962
$(40,04)$ como a cultivar que apresentou maiores valores para essa característica, apesar de não diferir da Embrapa $122(38,68)$. De acordo com Salla et al. (2007) a determinação dos teores de clorofila da folha é importante porque a atividade fotossintética da planta depende parcialmente da capacidade da folha em absorver luz. Nesse sentido, sugere-se que a cultivar Agrobel 962 por apresentar maior teor relativo de clorofila, indica melhor captação da radiação solar que durante o processo de fotossíntese, consequentemente, foi convertida em energia química na forma de ATP e NADPH (Taiz \& Zeiger, 2009).

Tabela 4. Resumo do teste F para as características: Índice relativo de clorofila (IRC); Teores de clorofila $a$ $(\mathrm{Chl} a)$, clorofila $b(\mathrm{Chl} b)$, clorofila total ( $\mathrm{Chl} \mathrm{t})$ e carotenoides (Carot) de cultivares de girassol sob diferentes regimes hídricos

\begin{tabular}{ccccccc}
\hline \multirow{2}{*}{ FV } & \multirow{2}{*}{ GL } & \multicolumn{5}{c}{ Quadrados Médios } \\
\cline { 3 - 7 } & & IRC & Chl $a$ & Chl $b$ & Chl t & Carot \\
\hline C & 2 & $44,0008^{* *}$ & $0,348^{\text {ns }}$ & $0,121^{\text {ns }}$ & $0,842^{\text {ns }}$ & $0,203^{* *}$ \\
RH & 3 & $5,523^{\text {ns }}$ & $0,251^{\text {ns }}$ & $1,716^{* *}$ & $3,047^{* *}$ & $0,032^{\text {ns }}$ \\
CxRH & 6 & $5,2650^{\text {ns }}$ & $0,124^{\text {ns }}$ & $0,281^{\text {ns }}$ & $0,547^{\text {ns }}$ & $0,020^{\text {ns }}$ \\
Resíduo & 36 & 9,005 & 0,160 & 0,290 & 0,654 & 0,016 \\
CV(\%) & & 7,80 & 21,28 & 16,41 & 15,97 & 17,67 \\
\hline
\end{tabular}

Nota: $\mathrm{FV}=$ Fontes de Variação, $\mathrm{GL}=$ Graus de Liberdade, $\mathrm{CV}=$ Coeficiente de variação, $\mathrm{C}=$ Cultivares, $\mathrm{RH}=$ Regimes Hídricos, ns $=$ não significativo $\mathrm{e}^{* *}=$ significativo $(\mathrm{p}<0,01)$ pelo teste $\mathrm{F}$.

Não foram constatadas diferenças significativas entre as cultivares e, entre os regimes hídricos quando isolados para os teores de clorofila $a$, bem como da interação desses. Contudo, verificou-se efeito significativo $(\mathrm{p}<0,01)$ dos regimes hídricos para os teores de clorofila $b$ e clorofila total, e diferença entre as cultivares para os teores de carotenoides (Tabela 4). Para os teores de clorofila $b$ houve crescimento linear em função dos regimes hídricos (Figura 1A), apresentando valores estimados de 2,$87 ; 3,14 ; 3,41$ e $3,69 \mathrm{mg} \mathrm{g}^{-1}$ $\mathrm{MF}$, respectivamente, para os regimes de $40,60,80$ e $100 \%$ da capacidade de campo; obtendo incremento de $28,57 \%$ do menor para o maior regime hídrico. Esses resultados corroboram com Magalhães et al. (2010) que observaram em genótipos de sorgo uma redução de $44,84 \%$ no conteúdo de clorofila após um período de estresse hídrico, evidenciando que a redução do conteúdo

Maia Junior et al., v.10, n.36, p. 105-112, Dourados, 2017 


\section{Revista Agrarian}

ISSN: 1984-2538

de clorofila está associada à restrição de água às plantas.

Assim como para a clorofila $b$, para a clorofila total também houve crescimento linear à medida que se elevou a umidade do solo (Figura 1B), sendo estimados valores de 4,52; 4,88; 5,24 e $5,60 \mathrm{mg} \mathrm{g}^{-1} \mathrm{MF}$, respectivamente, nos regimes de $40,60,80$ e $100 \%$ cc, com incremento de $23,89 \%$ no intervalo compreendido entre o menor e o maior nível hídrico. Os resultados encontrados nesse estudo condizem com o relatado por Hendry \& Price (1993), em que o déficit hídrico é caracterizado como um dos estresses ambientais responsáveis pela perda de pigmentos nas folhas propiciando assim, para que o ciclo de vida da planta seja modificado.

Tendo as cultivares apresentado redução nos teores de clorofila $b$ e clorofila total em função da limitação hídrica, presume-se que as plantas cultivadas nessas condições tenham perdido parcialmente a capacidade de fixação da radiação luminosa, fato de extrema importância para a produtividade primária, uma vez que a clorofila $b$ auxilia a clorofila $a$ na transferência de energia (Raven, 1983) sendo a clorofila $a$, a principal molécula responsável pela realização da fotossíntese (Taiz \& Zeiger, 2009), embora não tenha se observado efeito dos regimes hídricos para o teor de clorofila $a$.

A partir da diferença observada entre as cultivares para os teores de carotenoides (Tabela

A

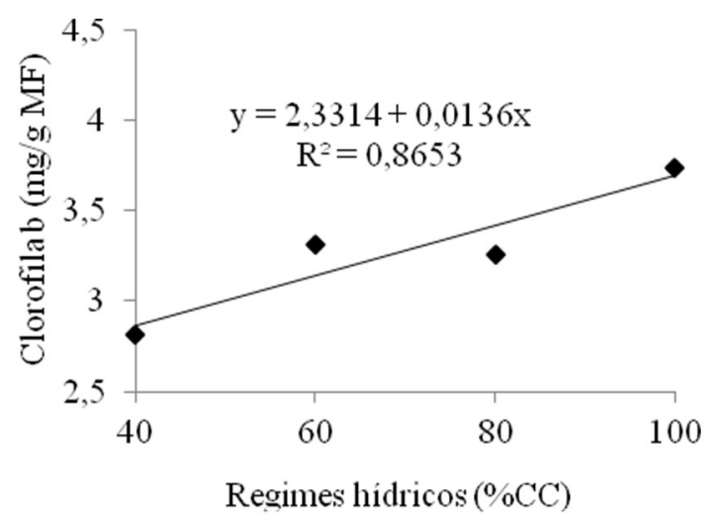

4), constatou-se superior para esta característica a cultivar Agrobel 962, seguida da BRS Gira 26 e Embrapa 122 com valores de 0,84; 0,72 e 0,61 mg $\mathrm{g}^{-1} \mathrm{MF}$, respectivamente. Os carotenoides são pigmentos acessórios que têm como uma de suas funcionalidades a proteção da clorofila no tocante à fotooxidação (Marenco \& Lopes, 2009). Assim, infere-se que a cultivar Agrobel 962, em detrimento as demais, apresentou mecanismo de defesa passível de evitar a destruição das moléculas de clorofila $a$, devido ao maior teor de carotenoides $\left(0,84 \mathrm{mg} \mathrm{g}^{-1} \mathrm{MF}\right)$, muito embora não se tenha observado efeito no teor de clorofila $a$ por ocasião dos regimes hídricos.

Estão dispostos na tabela 5 os resultados correspondentes às correlações, onde é possível verificar que houve correlação linear, forte, apenas entre o índice relativo de clorofila (SPAD) e o teor de clorofila total com $r=0,71$. Esses resultados demonstram que o índice relativo de clorofila, analisado pelo índice SPAD, está relacionado ao teor de clorofila total $(a+b)$. Assim, uma vez que o índice SPAD é um método mais prático de análise do teor de clorofila, pois é um método não destrutivo, que não necessita de solventes e não demanda muito tempo, com base na correlação linear obtida, pode-se estabelecer uma equação que relacione esses dois importantes aspectos (Figura 2).
B

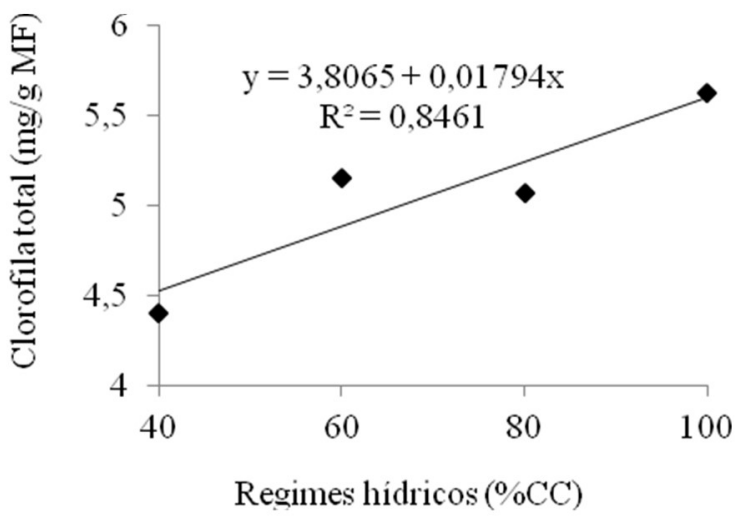

Figura 1. Teores de Clorofila $b(\mathrm{Chl} b)(\mathrm{A})$ e Clorofila total (Chl t) (B) de cultivares de girassol sob diferentes regimes hídricos, Campina Grande-PB, 2012. 


\section{(-) \\ Revista Agrarian \\ ISSN: $1984-2538$}

Tabela 5. Análise da correlação linear de Pearson (r) de aspectos fotossintéticos de cultivares de girassol entre os teores de clorofila $a, b$ e total e, o índice SPAD

\begin{tabular}{lc}
\hline Variáveis & Índice relativo de clorofila (SPAD) \\
\hline Teor de clorofila $a$ & $0,32^{*}$ \\
Teor de clorofila $b$ & $0,22^{*}$ \\
Teor de clorofila total & $0,71^{* *}$ \\
Teor de carotenoides & $0,31^{*}$ \\
\hline
\end{tabular}

Nota: ${ }^{* *}=$ correlação forte, ${ }^{*}=$ correlação fraca.

Dessa forma, o teor de clorofila total pode ser calculado indiretamente a partir dos valores do índice SPAD sem a necessidade de extração de folhas para a quantificação. Leonardo et al. (2013) também encontraram correlação entre o teor de clorofila e o índice SPAD em abacaxizeiro submetido a adubação nitrogenada. Esses resultados condizem ao reportado por Argenta et al.
(2001), os quais afirmam que o teor de clorofila pode ser determinado com auxílio do medidor portátil SPAD-502 que permite leituras instantâneas sem destruição do material vegetal de maneira simples e rápida, além de, apresentar-se tão eficiente quanto o obtido por espectrofotometria.

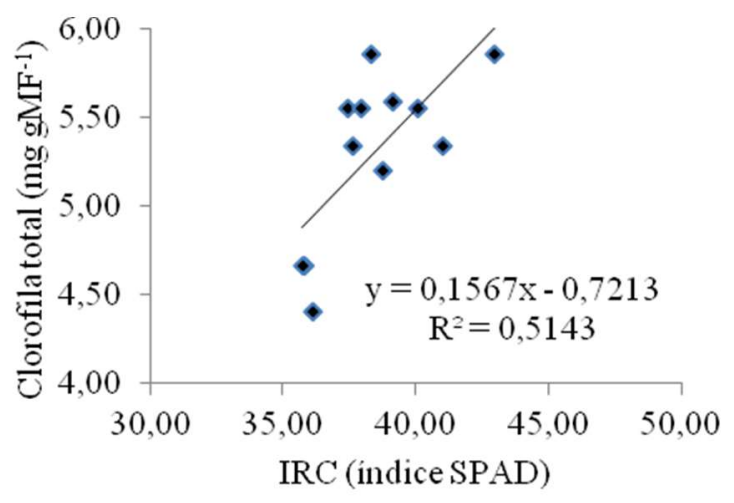

Figura 2. Correlação linear de Pearson entre índice relativo de clorofila (SPAD) e teor de clorofila total (mg $\mathrm{gMF}^{-1}$ ) em cultivares de girassol submetidas a diferentes regimes hídricos, Campina Grande, 2012.

\section{Conclusões}

O índice relativo de clorofila SPAD do girassol não foi afetado pelos regimes hídricos, no entanto, variou quanto às características genéticas das cultivares.

Os regimes hídricos não alteraram a fluorescência e o teor da clorofila $a$, entretanto, alteraram os teores de clorofila $b$ e total em plantas de girassol.

$\mathrm{O}$ teor de carotenoides variou entre cultivares, atribuindo-se às características particulares de cada material.

Houve correlação entre o índice de clorofila (SPAD) e o teor de clorofila total.

\section{Referências bibliográficas}

AMARANTE, L.; COLARES, D. S.; OLIVEIRA, M. L.; ZENZEN, I. L.; BADINELLI, P. G.; BERNARDI, E. Teores de Clorofilas em Soja Associada Simbioticamente com Diferentes Estirpes de Bradyrhizobium sob Alagamento. Revista Brasileira de Biociências, v.5, n. 2, p. 906-908, 2007.

ARGENTA, G.; SILVA, P.R.F.; BORTOLINI, C.G.; FORSTHOFER, E.L. \& STRIEDER, M.L. Relação entre teor de clorofila extraível e leitura do clorofilômetro na folha de milho. Revista Brasileira de Fisiologia Vegetal, v.13, p.11011106, 2001.

CAPONE, A.; SANTOS, E. R.; FERRAZ, E. C.; SANTOS, A. F.; OLIVEIRA, J. L.; BARROS, H. 


\section{(ㅇ) \\ Revista Agrarian \\ ISSN: 1984-2538}

B. Desempenho agronômico de cultivares de girassol no sul do Estado Tocantins. Journal of Biotechnology and Biodiversity, v.3, n.3, p. 1323, 2012.

CARNEIRO, M. M. L. C. Trocas gasosas e Metabolismo Antioxidativo em plantas de girassol em resposta ao déficit hídrico. 2011. 42p. Dissertação (Mestrado em Fisiologia Vegetal), UFPel, Pelotas.

CATUNDA, M.G.; FREITAS, S.P.; OLIVEIRA, J.G.; SILVA, C.M.M. Efeitos de herbicidas na atividade fotossintética e no crescimento de abacaxi (Ananas comossus). Planta Daninha, v. 23, n. 1, p. 115-121. 2005.

DICKMANN, L.; CARVALHO, M. A. C.; BRAGA, L. F.; SOUSA, M. P. Comportamento de sementes de girassol (helianthus annuus L.) submetidas a estresse salino. Revista de ciências agro-ambientais, v.3, p.64-75, 2005.

DUTRA, C. C.; PRADO, E. A. F.; PAIM, L. R.; SCALON, S. P. Q. Desenvolvimento de plantas de girassol sob diferentes condições de fornecimento de água. Semina: Ciências Agrárias, v. 33, n.1, p. 2657-2668, 2012.

EMPRESA BRASILEIRA DE PESQUISA AGROPECUÁRUIA. Centro Nacional de Pesquisa de Solos. Sistema Brasileiro de Classificação de Solos. Rio de Janeiro: Embrapa Solos, 2006. 412 p.

FERREIRA, D. F. SISVAR - sistema de análise de variância. Versão 3.04. Lavras: UFLA, 2000.

HENDRY, G. A. F; PRICE, A. H. Stress indicators: chorophylls and carotenoids. In: HENDRY, G. A. F.; GRIME, J. P. (Eds.) Methods in comparative plant ecology. London: Chapman \& Hall, 1993. p. 148-152.

HURA, T.; GRZESIAK, S.; HURA, K.; THIEMT, E.; TOKARZ, K.; DZONY, M. W. Physiological and biochemical tools useful in drought-tolerance detection in genotypes of winter triticale: accumulation of ferulic acid correlates with drought tolerance. Annals of Botany, v.100, p. 767-775, 2007.

LEITE, R. M. V. B. C.; BRIGHENTI, A. M.; CASTRO, C. Girassol no Brasil. Londrina: Embrapa Soja, 2005. 641 p.
LEONARDO, F. A. P.; PEREIRA, W. E.; SILVA, S. M.; COSTA, J. P. Teor de clorofila e índice SPAD no abacaxizeiro cv. Vitória em função da adubação nitrogenada. Revista Brasileira de Fruticultura, v. 35, n. 2, p. 377-383, 2013.

LICHTENTHALER, H. K. Chlorophylls and carotenoids: pigments of photosynthetic biomembranes. Methods of Enzymology, v.148, p.350-382. 1987.

LIRA, M. A.; CARVALHO, H. W. L.; CHAGAS, M. C. M.; BRISTOT, G.; DANTAS, J. A.; LIMA, J. M. P. Avaliação das potencialidades da cultura do girassol, como alternativa de cultivo no semiárido nordestino. Natal- RN: EMPARN, 2011. $40 \mathrm{p}$.

MAGALHÃES, P. C.; PEREIRA, F. J.; SCHAFFERT, R. E.; ALBUQUERQUE, P. E. P.; MAGALHÃES, J. V. Características morfofisiológicas e de produção de seis genótipos de sorgo submetidos ao estresse hídrico. Boletim de Pesquisa e Desenvolvimento, Sete Lagoas: Embrapa Milho e Sorgo, 22, 16p. 2010.

MARENCO, R. A.; LOPES, N. F. Fisiologia Vegetal. 3 ed. Viçosa, UFV. 2009, 486p.

PAES, J. M. V; ZITO, R.K.; LUCAS, F.T.; BORGES, B. M. N.; OLIVEIRA JR. A. B.; NUNES, M. C. de O. Avaliação de Cultivares de Girassol em Uberaba/MG. In: Reunião Nacional de Pesquisa de Girassol 2009, Pelotas-RS. Resumos. Embrapa Clima Temperado, p.18, 2009.

RAVEN, J. A. The transport and function of silicon in plants. Biological Reviews of the Cambridge Philosophical Society, v. 58, p. 179207, 1983.

SALLA, L.; RODRIGUES, J. C.; MARENCO, R. A. Teores de clorofila em árvores tropicais determinados com o SPAD-502. Revista Brasileira de Biociências, v. 5, p. 159-161, jul. 2007.

STREIT, N. M.; CANTERLE, L. P.; CANTO, M. W.; HECKTHEUER, L. H. H. As clorofilas. Ciência Rural, v.35, n.3, p.748-755, 2005.

TAIZ, L.; ZEIGER, E. Fisiologia Vegetal; tradução de Eliane Romanato Santarém et al., - 4. Ed. Porto Alegre: Artmed, 2009, 848p. 